\title{
Implementation and Evaluation of a RFID Smart Cabinet to Improve Traceability and the Efficient Consumption of High Cost Medical Supplies in a Large Hospital
}

\author{
María del Carmen León-Araujo ${ }^{1,2}$ - Elisa Gómez-Inhiesto ${ }^{1,2}$ • María Teresa Acaiturri-Ayesta ${ }^{1,2}$
}

Received: 18 April 2018 / Accepted: 3 April 2019 / Published online: 10 May 2019

(C) The Author(s) 2019, corrected publication 2019

\begin{abstract}
The efficiency of a smart cabinet with RFID technology to improve the information about inventory management for cardiothoracic surgery as well as for time savings, was assessed in a large reference hospital. In a 6-month study, the implemented operational RFID process (StocKey ${ }^{\circledR}$ Smart Cabinet) consisted of: i) product reception, registration and labelling in the general warehouse; ii) product storage in the cabinet and registered as inputs by radiofrequency; iii) products registered as outputs as required for surgery; iv) product assignment to a patient in the operating room; and v) return of products not used to the cabinet. Stock-outs, stock mismatches, urgent restocking, assignment of high-value medical products to patients, and time allocated by the supervisory staff to the stock management, were assessed on a monthly basis. $0 \%$ stock-outs and $0 \%$ stock mismatches using RFID were observed during the study. Monthly percentages of products requiring urgent restocking ranged from $0 \%$ to $13.3 \%$. No incorrect assignments to patients of surgery products or prostheses were detected. The percentage of correct assignments increased from $36.1 \%-86.1 \%$ to $100 \%$ in the first $4-5$ months. The total average time allocated by the supervisory staff to the whole logistic chain was reduced by 58\% (995 min with the traditional manual system vs. 428 min with RFID). The RFID system showed the ability to monitor both the traceability and consumption per patient of high-value surgery products as well as contributed to significant time savings.
\end{abstract}

Keywords RFID $\cdot$ High value product $\cdot$ Surgery $\cdot$ Traceability $\cdot$ Logistics

\section{Introduction}

Traditionally, all activities related to hospital logistics have been aimed at providing the health care staff with the necessary supplies to cover patient needs no matter the situation [26]. It is estimated that logistics represent up to $45 \%$ of a hospital's operational budget [7]. Nowadays, the perception that the patient can also be considered a client is gaining acceptance, so that health care centers are encouraged to develop

This article is part of the Topical Collection on Systems-Level Quality Improvement

María del Carmen León-Araujo

mariadelcarmen.leonaraujo@osakidetza.eus

1 Purchasing and Repository Department, Cruces University Hospital, Barakaldo, Spain

2 Departamento de Compras y Almacén, Hospital Universitario Cruces, Plaza de Cruces n 12, 48903 Barakaldo, Bizkaia, Spain sustainable management models in order to improve their efficiency, speed and reduce waste $[8,17]$. Therefore the adoption of novel technologies to account for the right stock, timely replenishment cycles, traceable flow of items and adequate consumption per patient is warranted. Such developments should ultimately have a positive impact on patient safety.

The automation of logistic systems enables progress towards efficient per patient management models, as it streamlines tasks associated with managing the full traceability of materials and obtaining information on consumption per patient that, without this automation, would be nearly impossible given the large number of resources and staff hours that would be required. Automatic identification technologies such as barcodes and more recently radio-frequency identification (RFID) have been developed to manage traceability efficiently. In contrast to barcode technology, which is still subject to operational problems related to manual processes [9], RFID technology offers accurate inventory visibility in real time, and immediate identification of the exact location of any individual item [2]. In addition, RFID-enabled cabinets can be 
used in the replenishment of consignment and high value supplies, such as in operating rooms [3]. Although RFID cabinets to track medical supplies have been in use since the early 2000s [24], studies evaluating their efficiency in the perioperative environment are scarce.

The University Hospital Cruces in Barakaldo (Spain), integrated into the Basque Health Service, has 981 beds and it is a regional reference hospital with services in complex specialties such as pediatric cardiac surgery, kidney and liver transplantation, and major burns. The hospital logistics manages approximately 15,000 stock references, of which around 4150 correspond to implantable devices and prostheses. Because of the high cost of these products, ensuring their traceability is of critical importance [1].

Recently the University Hospital Cruces has been investing in technologies for the improvement of logistics management through the automation of tasks and processes. Different types of automation equipment within all of the warehouses have been implemented. Thus, the peripheral warehouses (those with automated permanent inventory, located in the hospital Services and Departments) have successfully implemented the StocKey® Kanban "double bin" system with radiofrequency identification (Grifols, Barcelona, Spain), that allows inventory management (e.g., stock levels, batch, expiration dates) [22]. Taking a step further, the StocKey® RFID Smart Cabinet (Grifols) that provides access control for tracking high value products is being implemented to complement the Kanban system [15].

In this study, the efficiency of the RFID for the monitoring of traceability and consumption of high value surgical supplies was assessed in the cardiothoracic surgery operating rooms of the Hospital Cruces.

\section{Materials and methods}

\section{Objectives}

The primary objective of this study was to assess the improvement in the information about inventory management for cardiothoracic surgeries associated with the implementation of a simple and user-friendly automated system (StocKey® RFID Smart Cabinet) for the traceability and monitoring of medical supplies and products.

Specific endpoints included assessing the product traceability and consumption per patient of surgery supplies, control of lots, stocks and expiration dates of surgery supplies, as well as switching from paper-based records to electronic sheets. Finally, time savings in the supervisory staff derived from the RFID implementation were evaluated in comparison to the former non-automated logistics system of the Hospital Cruces.

\section{Description of the RFID system}

The StocKey® RFID Smart Cabinet consists of: i) a labeling station, that recognizes the information of the GS1 barcodes (format EAN \& HIBC), for the assignment of RFID labels with all information for the identification of the product item (e,g,. batch, serial number, expiration date); ii) a closed cabinet (Faraday cage with $816 \mathrm{~L}$ capacity in the large version) where products are stored (with a transparent door and lights inside to see products; flexible internal configuration of bins, shelves, dividers, hangers, etc.), secured with access controlled by a proximity card; all inputs and outputs are read by radiofrequency and send stock data when closing the door, as well as assigned to a user (nurse); iii) a patient assignment station in the operating room (with touchscreen, card reader and RFID reader) to check items assigned to a user and assign items to a patient by reading RFID tags, during the intervention; and iv) centralized software with web access for user management, integrations with the Hospital Informatics System and dashboard with KPI's (Key Performance Indicators) such as stock control and system alerts (expired products; products with early expiration date; products under minimal stock; stock-outs; products with medical alerts such as a recall; and users with items unassigned to patient for more than 48 h). The components of the StocKey® RFID Smart Cabinet are illustrated in Fig. 1.

The operational process from reception to assignment to patient and accounting is as follows:

1. The products are received in the general warehouse; the RFID labels are applied to each item and registered into the system through RFID and barcode reading.

2. Tagged products are stored in the RFID cabinet by the logistics staff who have the access card. As being registered as inputs by radiofrequency, the products are incorporated into the electronic inventory of the cabinet.

3. As a stored product is required for surgery, a nurse with the access card removes the item from the RFID cabinet, and both the user and item output are registered.

4. In the operating room, the item is assigned to a patient through the RFID reader at the patient station. The patient has been previously tagged and identified through hospital healthcare information and surgical programming systems of the Basque Health Service. If patient assignment was not performed on the day of the intervention, the RFID system posted the product as "not assigned".

5. The items not used in the intervention are returned to the RFID cabinet and automatically re-integrated into the electronic inventory without the need for manual registration.

6. The cost of the items used is automatically accounted for through integration with the economic management system of the hospital. The consumed items are restocked in the RFID cabinet on a daily basis. 
a

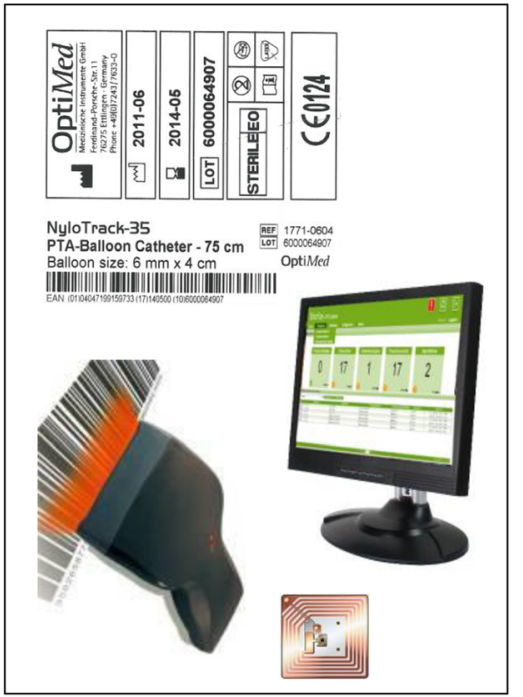

b

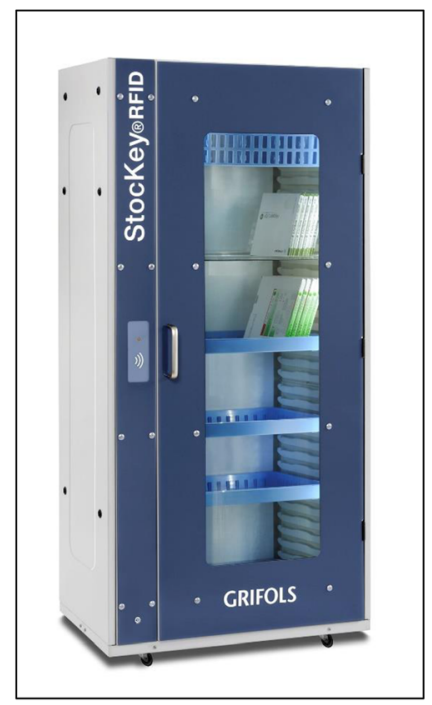

C

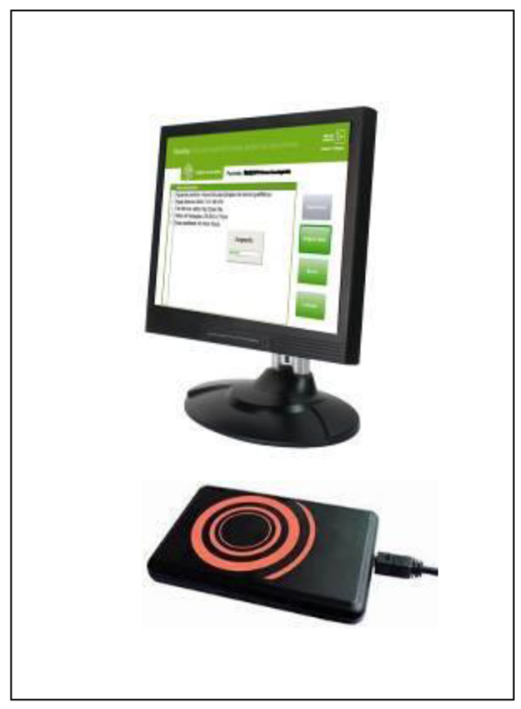

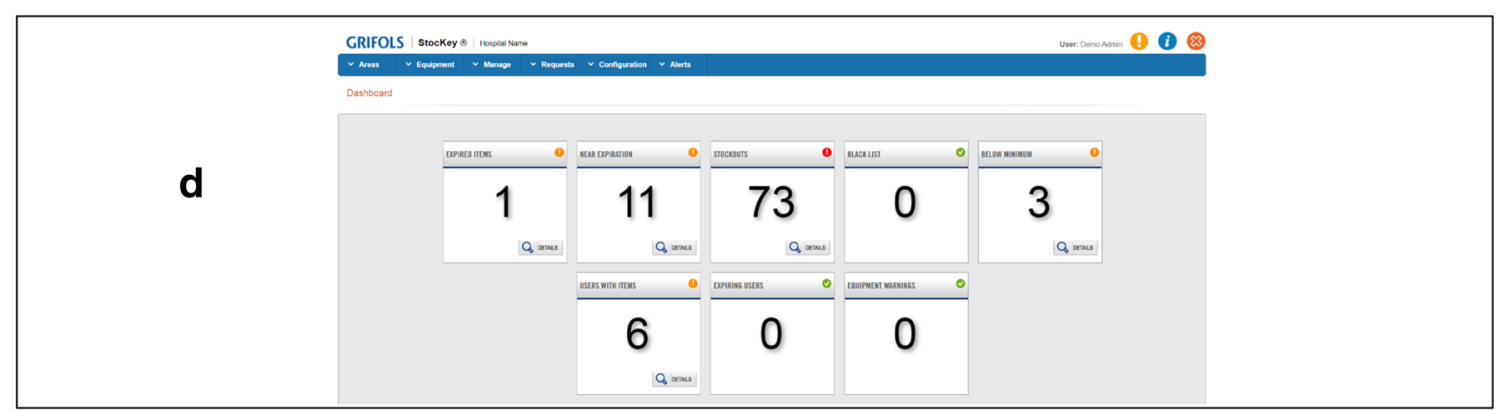

Fig. 1 The RFID Smart Cabinet components: A) labeling station; B) Closed cabinet; C) Patient assignment station; D) Dashboard with KPI's (Key Performance Indicators) and integrations with the Hospital Informatics System

7. Additionally, the products assigned can be ascribed to the clinical records of the patient via software integrations, as well as sharing the stock needs with the suppliers to allow for a quicker restocking.

\section{Implementation of the RFID system in the hospital}

The startup of the RFID was preceded by a pre-market pilot test carried out at the Hospital Universitario Cruces in a real world environment of an operating room.

In the implementation of the RFID, both the different actions to be taken as well as the timings were considered. The process took place from March 2014 to July 2015 and the most relevant steps are summarized as follows:

- Set up of an implementation timetable and selection of personnel.

- Validation of the RFID system in a test environment. This included the training of users, data registration, and integration of the system with the economic management and information systems of the hospital and the Basque Health Service.
- Definition and selection of high cost medical products for special monitoring by RFID: prostheses, implants, staplers, laparoscopy items, stents, catheters, valves.

- Parameterization of the variables to be RFID-monitored, with a full record of relevant data having an impact on the clinical safety of the patient: batch, serial number, expiration date, supplier, reference.

- Consideration of the appropriate places to install the RFID stations and installation of the RFID cabinets in the operating rooms.

Based on the experience acquired during the pilot test, areas for improvement detected through the RFID implementation were either applied immediately (such as those aimed at a more convenient and simpler use of the tool by the staff members as well as those involved in integration processes) or programmed for future developments.

\section{Evaluation of the RFID system}

From July to December 2015, the efficiency of the RFID for product traceability and assignment to patient (consumption) was tested in the cardiothoracic surgery operating rooms. The 
following variables were defined and calculated on a monthly basis:

- Medical products correctly assigned to patients: number of items assigned to patients with respect to total items consumed during an intervention.

- Prostheses correctly assigned to patients: number of prostheses assigned to patients with respect to total prostheses consumed during an intervention.

- Urgent restocking: number of products for urgent restocking (too few items in stock) with respect to the number of products requested.

- Stock mismatches: number of mismatches between products in the cabinet and RFID system stock with respect to the total number of products.

- Stock-outs: number of products not in stock with respect to the total number of products.

The monthly objectives to be reached were: i) $100 \%$ of correct assignments of surgery medical items and prostheses: ii) $0 \%$ of stock-outs and stock mismatches; and iii) no more than $15 \%$ of urgent replacements. Since the former nonautomated system did not generate data to design a comparative study, the stock-outs standard of the Hospital Cruces for healthcare supplies $(1 \%)$ was taken as an indicative figure, and the quality indicators for technologies applied to the outpatient hospital pharmacy as per the Spanish Society of Hospital Pharmacy [10] were considered as guidance.

In addition, the average monthly time allocated by the supervisory staff to the stock management during the study period (requests of products for cabinet, requests of other products, forms filling, receiving of products, product review, stock-outs) was calculated and compared to the equivalent period before the implementation of the RFID system.

\section{Results}

\section{RFID system set-up}

A total of 83 users were authorized to the RFID system, including supervisors and administrators with full access, warehouse workers with access to the labelling station, ancillary workers with access to the cabinet for restocking, and operating room nurses with access to the cabinet and patient assignment station. A total stock of 250 tagged items was set out in the RFID cabinet, of which 72 were surgery materials such as mechanical suture, sealing and cutting, while 178 were implantable materials (prostheses, implants, staplers, stents, catheters, heart valves). The estimated cost of the stored stock was $€ 369,211$.

\section{Product traceability and consumption results}

During the 6-month study period, the number of surgery products and prostheses consumed were 425 and 249, respectively.

Results of traceability variables related to stocks during the study period are shown in Table 1 . The objective of $0 \%$ stockouts and $0 \%$ stock mismatches was achieved throughout the study period. The percentage of products requiring urgent restocking was within the objective set, ranging from optimal $0 \%$ in November to $13.3 \%$ in December.

No incorrect assignments of surgery items or prostheses to patients were detected. The correct assignment of surgery items to patients increased from $36.1 \%$ to $100 \%$ in November while the correct assignment of prostheses to patients increased from $86.1 \%$ to $100 \%$ in October. During the subsequent months, the percentage of correct assignments slightly decreased. These results are detailed in Table 2 . The reasons for the few cases of unsuccessful assignment of the product to patient were essentially of a technical nature and data integration.

\section{Time allocation results}

The total average time allocated by the supervisory staff to the whole logistic chain was reduced by $58 \%$ (from $995 \mathrm{~min}$ with the traditional manual system to $428 \mathrm{~min}$ with the RFID system). The task most dramatically reduced was product request by the supervisory staff ( $100 \%$ reduction due to full automation), followed by product receiving by the supervisory staff $(56 \%$ reduction due to transfer of allocation to the logistics staff). Times of

Table 1 Results of traceability variables related to stocks as registered by the RFID during the study period

\begin{tabular}{|c|c|c|c|c|c|c|}
\hline & $\begin{array}{l}\text { July } \\
\text { n (\%) }\end{array}$ & $\begin{array}{l}\text { August } \\
\mathrm{n}(\%)\end{array}$ & $\begin{array}{l}\text { September } \\
\mathrm{n}(\%)\end{array}$ & $\begin{array}{l}\text { October } \\
\mathrm{n}(\%)\end{array}$ & $\begin{array}{l}\text { November } \\
\mathrm{n}(\%)\end{array}$ & $\begin{array}{l}\text { December } \\
\mathrm{n}(\%)\end{array}$ \\
\hline Urgent restocking & $2(11.8)$ & $1(6.3)$ & $1(4.8)$ & $3(13.0)$ & $0(0)$ & $2(13.3)$ \\
\hline Total requests & 17 & 16 & 21 & 23 & 17 & 15 \\
\hline Stock-outs & $0(0)$ & $0(0)$ & $0(0)$ & $0(0)$ & $0(0)$ & $0(0)$ \\
\hline Stock mismatches & $0(0)$ & $0(0)$ & $0(0)$ & $0(0)$ & $0(0)$ & $0(0)$ \\
\hline Total stock & 250 & 250 & 250 & 250 & 250 & 250 \\
\hline
\end{tabular}


Table 2 Results of the assignments of surgery products and prostheses to patients by the RFID during the study period

\begin{tabular}{|c|c|c|c|c|c|c|c|}
\hline & & $\begin{array}{l}\text { July } \\
\mathrm{n}(\%)\end{array}$ & $\begin{array}{l}\text { August } \\
\mathrm{n}(\%)\end{array}$ & $\begin{array}{l}\text { September } \\
\mathrm{n}(\%)\end{array}$ & $\begin{array}{l}\text { October } \\
\mathrm{n}(\%)\end{array}$ & $\begin{array}{l}\text { November } \\
\mathrm{n}(\%)\end{array}$ & $\begin{array}{l}\text { December } \\
\mathrm{n}(\%)\end{array}$ \\
\hline \multirow{4}{*}{$\begin{array}{l}\text { Assignment of surgery } \\
\text { products to patient }\end{array}$} & Correctly & $22(36.1)$ & $51(63.8)$ & 65 (92.9) & $68(82.9)$ & $70(100)$ & $52(83.9)$ \\
\hline & Incorrectly & $0(0)$ & $0(0)$ & $0(0)$ & $0(0)$ & $0(0)$ & $0(0)$ \\
\hline & Not assigned & $39(63.9)$ & $29(36.3)$ & $5(7.1)$ & $14(17.1)$ & $0(0)$ & $10(16.1)$ \\
\hline & Total & 61 & 80 & 70 & 82 & 70 & 62 \\
\hline \multirow{4}{*}{$\begin{array}{l}\text { Assignment of } \\
\text { prostheses to patient }\end{array}$} & Correctly & $31(86.1)$ & $17(85.0)$ & $29(93.5)$ & $51(100)$ & $45(93.8)$ & 40 (88.9) \\
\hline & Incorrectly & $0(0)$ & $0(0)$ & $0(0)$ & $0(0)$ & $0(0)$ & $0(0)$ \\
\hline & Not assigned & $5(13.9)$ & $3(15.0)$ & $2(6.5)$ & $0(0)$ & $3(6.2)$ & $5(11.1)$ \\
\hline & Total & 36 & 20 & 31 & 51 & 48 & 45 \\
\hline
\end{tabular}

the other monitored tasks were not affected by the RFID system. These results are summarized in Table 3.

\section{Discussion}

In the context of economic adjustments and resource optimization in global healthcare without jeopardizing patient safety, reliable systems to monitor the consumption of materials through ensuring their full traceability are needed $[13,28]$. The RFID automation of logistic systems represents a significant step forward in patient-focused models for consignment and high value product management [4]. Benefits of RFID implementation address patient safety issues (e.g., preventing the implant of a recalled or outdated product or a product stock-out during the surgical intervention), healthcare providers (e.g., fewer manual processes and non-clinical tasks), and financial status (e.g., preventing product wastage due to expiration or obsolescence, excess of stock or stock diversion) $[14,16,25]$.

In this study, the RFID system demonstrated not only having the capacity for full traceability and monitoring of high value medical products in the perioperative cardiothoracic surgery, but also the ability to significantly reduce the time that the clinical staff allocates to the tasks of the logistic chain.

RFID technologies in hospital logistics have been commonly applied in management of pharmaceutical inventories [6], trace- ability of medication distribution from warehouse to pharmacy $[18,23]$, and from pharmacy to the patient [12, 19-21]. With a scarcity of empirical studies on RFID use for stock management of high value surgery medical products, our results would support the implementation of a RFID smart cabinet for this aim. The RFID was proven highly efficient for the control of stocks during the study period, since no stock-outs and no stock mismatches were observed. The products were fully traceable from their reception in the general warehouse, to assignment to surgery patient, or re-integration into the electronic inventory if not used. In addition, the system effectively recorded the consumption of products per surgery and per patient.

Management of critical products through RFID was aimed to achieve a minimal percentage of urgent re-stocking. Our results showed a reasonable range of $0 \%$ to $13.3 \%$ values, although there was a margin for improvement to optimal $0 \%$ throughout considering that the RFID implementation project is in the very early stages. It should be taken into account that unexpected shortages of surgical items may have a severe impact in patient safety.

In the operating room, no incorrect assignment of surgery products and prostheses to patients were observed during the study period, which highlights the contribution of the RFID system to patient safety. The percentage of correct assignments increased from $36.1 \%-86.1 \%$ to $100 \%$ in the first 4 5 months, which represented good progression. The remaining percentage of not assigned products during some months
Table 3 Total average time allocated to the whole logistic chain, before (manual system) and after the implementation of the RFID

\begin{tabular}{llllll}
\hline Task & \multicolumn{2}{l}{ Manual system } & & With RFID & \\
\cline { 2 - 3 } \cline { 5 - 6 } & Responsible & Allocation time (min) & & Responsible & Allocation time (min) \\
\hline Product request for cabinet & Supervisor & 400 & Automated & 0 \\
Requests of other products & Supervisor & 20 & Supervisor & 20 \\
Forms filling & Supervisor & 220 & Supervisor & 220 \\
Products receiving & Supervisor & 300 & Logistics & 133 \\
Product review & Supervisor & 15 & Supervisor & 15 \\
Stock-outs & Supervisor & 35 & Supervisor & 35 \\
Other tasks & Supervisor & 5 & Supervisor & 5 \\
Total & & 995 & & 428 \\
\hline
\end{tabular}


was essentially due to technical reasons and data integration. Further corrective action was applied as programmed in the RFID implementation program. Nevertheless, the observed results fell within what could be expected at the very early stages of the implementation project.

In addition to improved product traceability and increased patient safety, better staff time management was one of the focuses of RFID implementation. Nurse activities such as product administration and documentation represent targets for improving efficiency [11]. Our study demonstrated a significant reduction of time allocation of the supervisory staff nurses after the implementation of the RFID. Importantly, this time was mainly saved from administrative and warehouse tasks. Increasing the efficiency of nursing care delivery is essential to hospital function and patient safety.

RFID implementation in surgery is not without risks. In addition to organizational issues as we encountered, environmental (e.g., interference with radio waves and electromagnetic fields, inhibition of temporary pacing systems) and technical (e.g., reading errors; breakdown of computer networks) hazards also need to be considered when adopting RFID in surgery facilities [5, 27]. In the case of StocKey® RFID, it is a Faraday cage that shields their contents from electronic interferences. Finally, our study was limited to our hospital and three operating rooms, so extrapolation of conclusions should be made with caution.

In summary, the RFID smart cabinet tool for inventory management demonstrated its capacity for the traceability and monitoring of high-value medical products stock, from warehouse to patient assignment in the cardiothoracic operating room. Moreover, the RFID smart cabinet significantly reduced the time allocated to the logistic chain tasks by the clinical staff. We believe that the implementation of a RFID ultimately had a positive impact on the economic management of the hospital and patient's safety.

Acknowledgements The authors acknowledge the following people at the Hospital Cruces for their contribution to the study: Esther García Garcia and Leyre Marquez Bilbao. Jordi Bozzo PhD, CMPP (Grifols) is acknowledged for medical writing and editorial assistance in the preparation of this manuscript, under the direction of the authors.

Author's Contributions MCLA was the principal investigator. EGI and MTAA contributed to the concept and design of the study and data validation. All authors critically revised the manuscript and approved the final version

Open Access This article is distributed under the terms of the Creative Commons Attribution 4.0 International License (http:// creativecommons.org/licenses/by/4.0/), which permits unrestricted use, distribution, and reproduction in any medium, provided you give appropriate credit to the original author(s) and the source, provide a link to the Creative Commons license, and indicate if changes were made.

\section{Compliance with Ethical Standards}

Conflict of Interest This study was supported and funded by Grifols. The authors declare that they have no conflict of interest.

\section{References}

1. Anonymous Global Traceability Standard for Healthcare. Business Process and System Requirements for Supply Chain Traceability. GS1 Standard. Issue 1.2.0; 2013. Available at: http://www.gs1.org/ docs/gsmp/traceability/Global_Traceability_Standard_Healthcare. pdf.

2. Bendavid, Y., and Boeck, H., Using RFID to Improve Hospital Supply Chain Management for High Value and Consignment Items. Proc. Comput. Sci. 00:1-8, 2011.

3. Bendavid, Y., Boeck, H., and Philippe, R., Redesigning the replenishment process of medical supplies in hospitals with RFID. Business Process Manag. J. 16(6):991-1013, 2010.

4. Bendavid, Y., Boeck, H., and Philippe, R., RFID-enabled traceability system for consignment and high value products: A case study in the healthcare sector. J. Med. Syst. 36(6):3473-3489, 2012.

5. Bertrand, E., and Schlatter, J., Map of risks for the implementation of radio-frequency identification: Application of ancillaries in the University Hospital Jean Verdier. Die Pharmazie 65(1):64-68, 2010.

6. Çakici, Ö. E., Groenevelt, H., and Seidmann, A., Using RFID for the management of pharmaceutical inventory - system optimization and shrinkage control. Decis. Support Syst. 52:842-852, 2011.

7. Closs, D. J., How can supply chain managers help the healthcare industry? Logis. Quart. 15:26-27, 2009.

8. Coustasse, A., Tomblin, S., and Slack, C., Impact of radiofrequency identification (RFID) technologies on the hospital supply chain: A literature review. Perspect. Health Inform. Manag. 10:1d, 2013.

9. Dehoratius, N., and Raman, A., Inventory record inaccuracy: An empirical analysis. Manag. Sci. 54(4):627-641, 2008.

10. Govindarajan, R., Perello-Junca, A., Pares-Marimon, R. M. et al., Process management in the hospital pharmacy for the improvement of the patient safety. Revista de calidad asistencial : organo de la Sociedad Espanola de Calidad Asistencial 28(3):145-154, 2013.

11. Hendrich, A., Chow, M. P., Skierczynski, B. A., and Lu, Z., A 36hospital time and motion study: How do medical-surgical nurses spend their time? Perm. J 12(3):25-34, 2008.

12. Hwang, Y., Yoon, D., Ahn, E. K., Hwang, H., and Park, R. W., Provider risk factors for medication administration error alerts: Analyses of a large-scale closed-loop medication administration system using RFID and barcode. Pharmacoepidemiol. Drug Saf. 25(12):1387-1396, 2016.

13. Jeddi, F. R., Hajbaghery, M. A., Akbari, H. et al., Technological feasibility of a nursing clinical information system. Electron. Phys. 8(9):2942-2949, 2016.

14. Kumar, S., Livermont, G., and Mckewan, G., Stage implementation of RFID in hospitals. Technol. Health Care : Off. J. Eur. Soc. Eng. Med. 18:31-46, 2010.

15. Landry, S., and Beaulieu, M., Achieving lean healthcare by combining the two-bin kanban replenishment system with RFID technology. Intern. J. Health Manag. Inf. 1:85-98, 2010.

16. Liu, C. C., Chang, C. H., Su, M. C. et al., RFID-initiated workflow control to facilitate patient safety and utilization efficiency in operation theater. Comput. Methods Programs Biomed. 104(3):435442, 2011.

17. Manos, A., Sattler, M., and Alukal, G., Make healthcare lean. Qual. Prog. 39:24-30, 2006.

18. Martin, D., Alcarria, R., Sanchez-Picot, A. et al., An ambient intelligence framework for end-user service provisioning in a hospital pharmacy: A case study. J. Med. Syst. 39(10):116, 2015.

19. Martinez Perez, M., Cabrero-Canosa, M., Vizoso Hermida, J. et al., Application of RFID technology in patient tracking and medication traceability in emergency care. J. Med. Syst. 36(6):3983-3993, 2012. 
20. Martinez Perez, M., Vazquez Gonzalez, G., and Dafonte, C., Evaluation of a tracking system for patients and mixed intravenous medication based on RFID technology. Sensors (Basel, Switzerland) 16, 2016.

21. Martinez Perez, M., Vazquez Gonzalez, G., and Dafonte, C., Safety and Traceability in Patient Healthcare through the Integration of RFID Technology for Intravenous Mixtures in the PrescriptionValidation-Elaboration-Dispensation-Administration Circuit to Day Hospital Patients. Sensors (Basel, Switzerland) 16, 2016.

22. Mitka, E., Application of Kanban System on a hospital pharmacy. Hell. J. Nucl. Med. 18(Suppl 1):4-10, 2015.

23. Moreno, A., Angulo, I., Perallos, A., Landaluce, H., Zuazola, I. J. G., Azpilicueta, L., Astrain, J. J., Falcone, F., and Villadangos, J., IVAN: Intelligent van for the distribution of pharmaceutical drugs. Sensors (Basel, Switzerland) 12(5):6587-6609, 2012.

24. Nagy, P., George, I., Bernstein, W., Caban, J., Klein, R., Mezrich, R., and Park, A., Radio frequency identification systems technology in the surgical setting. Surg. Innov. 13(1):61-67, 2006.
25. Southard, P. B., Chandra, C., and Kumar, S., RFID in healthcare: A six sigma DMAIC and simulation case study. Int. J. Health Care Qual. Assur. 25(4):291-321, 2012.

26. Teisberg, E. O., Redefining health care: creating value-based competition on results. Boston MA, USA: Harvard Business Review Press, 2006.

27. Williams, M. R., Atkinson, D. B., Bezzerides, V. J., Yuki, K., Franklin, K., Casta, A., and Alexander, M. E., Pausing with the gauze: Inhibition of temporary pacemakers by radiofrequency scan during cardiac surgery. Anesth. Analges. 123(5):1143-1148, 2016.

28. Zhao, T., Zhang, X., Zeng, L., Xia, S., Hinton, Jr., A. O., and Li, X., Applications for radio-frequency identification technology in the perioperative setting. AORN J. 99(6):764-781, 2014.

Publisher's Note Springer Nature remains neutral with regard to jurisdictional claims in published maps and institutional affiliations. 